Article

\title{
Effects of Ethanol Concentration on Organosolv Lignin Precipitation and Aggregation from Miscanthus $x$ giganteus
}

\author{
Muhammad Hazwan Hamzah $1,2,3, * \mathbb{D}$, Steve Bowra ${ }^{4}$ and Philip Cox ${ }^{5}$ \\ 1 Department of Biological and Agricultural Engineering, Faculty of Engineering, Universiti Putra Malaysia, \\ UPM Serdang 43400, Selangor, Malaysia \\ 2 SMART Farming Technology Research Centre, Faculty of Engineering, Universiti Putra Malaysia, \\ UPM Serdang 43400, Selangor, Malaysia \\ 3 School of Chemical Engineering, University of Birmingham, Edgbaston B15 2TT, UK \\ 4 Phytatec (UK) Ltd., Plas Gogerddan, Aberystwyth SY23 3EB, UK; steve.bowra@phytatec.com \\ 5 Chemical Engineering, University of Wolverhampton, Wulfruna Street, Wolverhampton WV1 1LY, UK; \\ P.W.Cox@wlv.ac.uk \\ * Correspondence: hazwanhamzah@upm.edu.my; Tel.: +603-97696422
}

Received: 23 April 2020; Accepted: 19 June 2020; Published: 16 July 2020

\begin{abstract}
This work assesses the behavior of organosolv lignin aggregates derived from Miscanthus $x$ giganteus using different ethanol concentrations (10\%, 25\%,50\%, and $75 \%$ by volume). The percentage of lignin recovery was found to decrease from $75.8 \%$ to $71.4 \%$ and $25.1 \%$, as the ethanol concentration was increased from $10 \%$ to $25 \%$ and $50 \%$, respectively. Increasing the ethanol concentration further to $75 \%$ led to zero recovery. The purity of the precipitated lignin was consistently found to be $\geq 90 \%$. Lignin derived from the dried supernatant obtained at 50\% ethanol concentration resulted in high lignin purity (51.6\%) in comparison with the other ethanol concentrations used. Fourier transform infrared spectroscopy analysis showed that the precipitated lignin and dried supernatant at 50\% ethanol concentration possessed the highest peak intensity apportioned to wavenumber of lignin as compared to that of at $25 \%$ and $10 \%$ ethanol concentrations, and the results linked with the percentage of lignin purity. The results of particle size analysis for precipitated lignin demonstrated particle sizes of 306,392 , and $2050 \mathrm{~nm}$ for $10 \%, 25 \%$, and 50\% ethanol concentrations, respectively, and the remaining supernatant with average particle sizes of 1598, 1197, and $875 \mathrm{~nm}$, respectively. These results were verified with the morphology of lignin macromolecules in scanning electron microscopy images. Results of the particle size distribution of lignin revealed that the overall size of lignin aggregates decreased with decreasing ethanol concentration. In summary, these findings suggest that ethanol concentration affected the behavior of lignin aggregates in water-ethanol solution.
\end{abstract}

Keywords: lignocellulosic; organosolv; lignin; aggregates; purity; concentration

\section{Introduction}

The demand for finite resources such as fossil fuels and natural gas are growing in most countries in the world in spite of the current energy crisis. The increasing awareness of the need for renewable and sustainable sources of energy has driven interest in lignocellulosic second-generation bioethanol. Miscanthus sp., a genus comprising of about 25 species has been proven as one of the biomass crops having high biomass energy potentials [1]. Miscanthus $x$ giganteus (MxG), a hybrid between Miscanthus sinensis and Miscanthus sacchrisflorus, is a promising high-yield lignocellulosic biomass crop that is currently used as a solid fuel used in co-firing power stations [2]. When compared with other genotypes, $M x G$ has a wide range of potential benefits including the possibly unique and exclusive 
trait for adaptation to climate and environmental conditions, low levels of nutrients needed, soil carbon sequestration, and ease of harvesting and handling [3-6]. MxG also has an efficient rhizome system, which plays a key role as a nutrient reserve for the annual shoot growth in the growing season [7]. Miscanthus sp., which can be obtained mainly from the Europe and the United States, has enormous potential to become a feedstock to support second-generation bioethanol production. Similarly, the concept of biorefining has been identified as a method whereby cellulose, the substrate for ethanol production, can be recovered along with other renewable bio-based chemical building blocks, hemicellulose and lignin, thus potentially improving the overall economy of bioethanol production.

Within the integrated biorefinery concept, an area of research that has gained significant interest is the processing of lignin which, as mentioned earlier, is the second most abundant natural polymer after cellulose and hemicellulose [8]. Currently, lignin is traditionally viewed as the by-product of paper and pulp processes. However, with the emergence of second generation bioethanol production, large quantities of lignin will be created. Lignin isolated via different extraction methods can vary widely in terms of chemical composition and molecular structure. The differences also affect the physical properties such as solubility and particle size. Therefore, in the context growing interest in developing value added uses for lignin, this work focuses on characterizing lignin extracted using a modified organosolv method [9], particularly emphasizing the formation of aggregates. There is insufficient information available that describes the association behavior of lignin in solution, which depends on the solvent properties and lignin structure [10].

Understanding and interpreting the assembly of lignin macromolecules in solution are relevant and significant, as the heterogeneity and complexity of lignin structure, unique chemical reactivity, and the unknown molecular characteristics of lignin become the greatest bottlenecks in the utilization of lignin in producing various useful and renewable materials in the industry [11-13]. Previously, numerous studies on lignin aggregates have been conducted in conjunction with different types of methods and sources of lignin such as the aggregation and assembly of alkali lignin using iodine as probe [14], the impact of lignin source on its self-assembly in d-DMSO solution [10], and the aggregation of acetylated lignins in N,N-dimetylacetamide in the presence of salts [15]. A crucial physicochemical property of organosolv lignin which becomes the subject matter for this work is the higher solubility of organosolv lignin in organic solvents [16]. Organosolv lignin has a tendency to aggregate in most solvents, affecting the lignin recovery process, the biodegradation processes, and the preparation of lignin-based materials.

In this work, the resulting soluble lignin extract from delignification process was fractionated according to different ethanol solubilities under centrifugation, thereby generating two fractions: the precipitated fraction and supernatant fraction. Characterization of the resulting fractions was carried out by Klason lignin assay, Fourier transform infrared spectroscopy (FTIR), scanning electron miscroscopy (SEM), and particle size analysis. Specifically, the study compared the purity, lignin recovery, chemical structure, and especially particle size and morphology characterization for the resulting fractions.

\section{Materials and Methods}

\subsection{Materials}

The lignocellulosic biomass used was air-dried. The $M x G$ was provided by the Institute of Biological, Environmental and Rural Sciences (IBERS, UK) in collaboration with Phytatec (UK) Ltd. The biomass was harvested in Aberystwyth, Wales, United Kingdom and kept in a cool, dry, and dark place throughout the study. Nitrogen (compressed oxygen free nitrogen, BOC, UK), and carbon dioxide (vapor withdrawal, BOC, UK) had $\geq 99.8 \%$ purity. Sulfuric acid (72\%) (Fluka-Sigma Aldrich, UK) and absolute ethanol (Fisher Scientific, UK) were used as reagents. 


\subsection{Methodology}

\subsubsection{Biomass Preparation}

Prior to hydrolysis, the $M x G$ was mixed in distilled water and then warmed to $50{ }^{\circ} \mathrm{C}$ to soften the grass. The mixture was then soaked for $20 \mathrm{~min}$ to rehydrate the grass. The mixture was milled for $3 \mathrm{~min}$ in a domestic blender to reduce the particle size of the material. The grinding conditions of the temperature, soaking time, grinding time, and the solid-to-liquid ratio were previously optimized to yield an average particle size of $500 \mu \mathrm{m}$ [17].

The $M x G$ slurry was placed inside the reactor directly after the sample preparation at $120^{\circ} \mathrm{C}$. The sequentially processed $M x G$ obtained at $120^{\circ} \mathrm{C}$ was used for biomass hydrolysis at $180^{\circ} \mathrm{C}$ and $200^{\circ} \mathrm{C}$. Subsequently, the $M x G$ was mixed in water and a 1:1 ethanol-water solution for $180^{\circ} \mathrm{C}$ and $200^{\circ} \mathrm{C}$, respectively, by warming to $50^{\circ} \mathrm{C}$ and for a wetting time of $5 \mathrm{~min}$ prior to each hydrolysis step.

\subsubsection{Biomass Hydrolysis}

The steps taken in extracting lignin in this work are outlined in Figure 1.

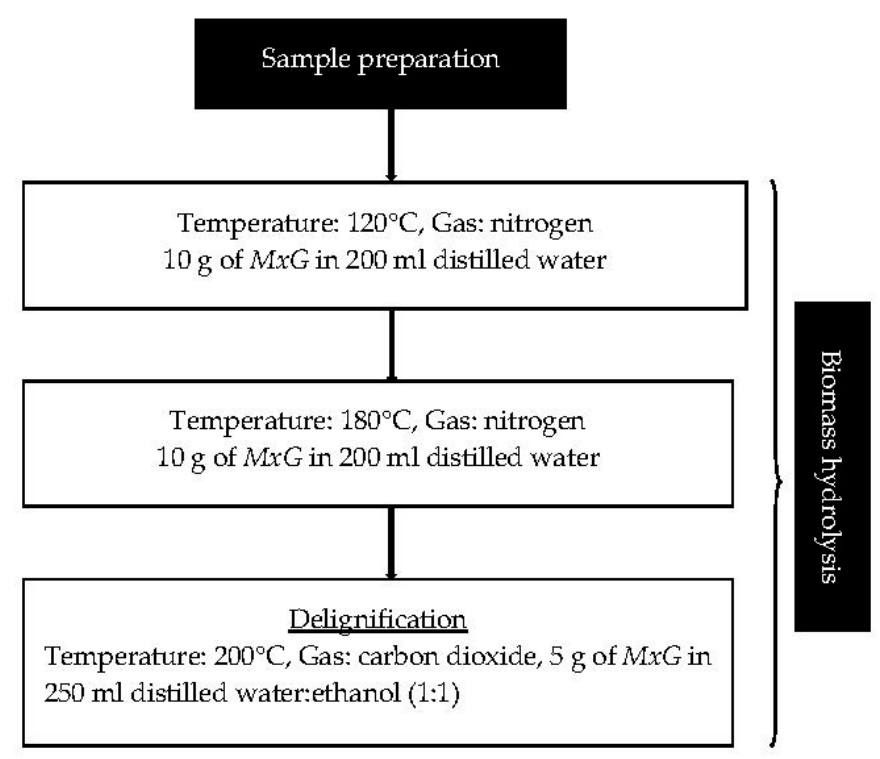

Figure 1. Steps taken in lignin extraction.

The $M x G$ slurry was transferred to a $500 \mathrm{~mL}$ stirred pressure vessel (Alloy C276, Parr, IL, USA). The reactor was closed and pressurized with desired gas to 50 bar. The set point temperature was increased to the set temperature and was kept stable during the reaction time by a controller (4386, Parr). After the reaction, the reactor temperature was decreased through a cooling system with a cooling coil inside the pressure vessel in which a coolant flew at an initial $-7^{\circ} \mathrm{C}$. When the temperature fell below $50{ }^{\circ} \mathrm{C}$, the reactor was depressurized slowly to atmospheric pressure before the reactor was opened. Finally, the solution and solid fibers were separated using a laboratory test sieve (BS410-1 size $45 \mu \mathrm{m}$, Endecotts Ltd., England) for biomass hydrolysis at $120^{\circ} \mathrm{C}$ and $180{ }^{\circ} \mathrm{C}$. The solid fibers were placed in the drying cabinet $\left(65^{\circ} \mathrm{C}\right)$ until it reached constant weight. The liquid fraction or filtrate for biomass hydrolysis at $200{ }^{\circ} \mathrm{C}$ was recovered by vacuum filtration through a Pyrex sintered disc of porosity 2, rinsed with mixture of distilled water: ethanol (1:1).

The $M x G$ was treated through a three-stage temperature profile sequential batch extraction method adapted from Hamzah et al. [9] to differentially separate extractives, hemicellulose, cellulose, and lignin. The first step applied subcritical water (SCW) at $120^{\circ} \mathrm{C}$ with an equilibrium time of $30 \mathrm{~min}$ and 50 bar of nitrogen gas to remove water-soluble extractives that could have interfered with the isolation and later analytical steps. The second step used a SCW at a regime of $180^{\circ} \mathrm{C}$ and a reaction time of 
$30 \mathrm{~min}$ under 50 bar of nitrogen gas to hydrolyze hemicelluloses prior to delignification. The final step involved lignin extraction via a SCW with associated modifiers using a 1:1 ethanol-water mixture at $200{ }^{\circ} \mathrm{C}$, a reaction time of $60 \mathrm{~min}$, and 50 bar of carbon dioxide gas. The nitrogen gas was used in SCW to maintain the constant pressure inside the reactor and to ensure that water remain as liquid [18]. In lignin extraction, carbon dioxide under pressure creates carbonic acid that serves as a catalyst for hydrolysis reaction $[17,19]$.

\subsubsection{Lignin Precipitation}

The lignin precipitation method was adapted from Roque [17]. The $50 \%$ ethanol concentration of soluble lignin extract obtained after vacuum filtration was placed in a freezer at $-20{ }^{\circ} \mathrm{C}$ for $2 \mathrm{~h}$, after which the ethanol concentration was adjusted to either $10 \%$ and $25 \%$ by adding distilled water, and $75 \%$ by adding ethanol. The lignin was recovered using a J2-21 centrifuge (Beckman, Indianapolis, IN, USA) with a JA- 10 rotor at $4{ }^{\circ} \mathrm{C}$ and at 10,000 revolutions per minute with 17,700 relative centrifugal force (RCF) for $10 \mathrm{~min}$. The remaining supernatant was dried at $65^{\circ} \mathrm{C}$ for further Klason lignin assay and FTIR analysis. The resulting precipitated lignin was air-dried and stored in $2 \mathrm{~mL}$ Eppendorf tubes at room temperature and later analyzed by a Klason lignin assay and FTIR analysis. The amount of precipitated lignin was compared to the total amount of lignin in the soluble fraction (precipitated lignin and dried supernatant), which gives the percentage of lignin recovery using Equation (1):

$$
\text { Percentage of lignin recovery }(\%)=\frac{A_{l}}{A_{l}+A_{s}} \times 100 \% \text {, }
$$

where $A_{l}$ is the amount of precipitated lignin (g) and $A_{s}$ is the amount of lignin derived from dried supernatant $(\mathrm{g})$.

\subsubsection{Klason Lignin Determination}

After the hydrolysis experiments, the precipitated lignin and dried supernatant was analyzed for lignin content using the Klason lignin assay following the Determination of Structural Carbohydrates and Lignin in Biomass Laboratory Analytical Procedure (NREL/TP-510-42618) [20].

\subsubsection{FTIR Analysis}

The FTIR analysis was carried out on the samples without any special pre-treatment. The IR spectra were determined using a spectrometer (FTIR-6300, JASCO, Easton, MD, USA) over a wavenumber ranging from $4000 \mathrm{~cm}^{-1}$ to $600 \mathrm{~cm}^{-1}$. The resolution was $4 \mathrm{~cm}^{-1}$ and 32 scans were averaged. The precipitated lignin and dried supernatant of different ethanol concentration were analyzed for chemical structure characterization. Principle component analysis (PCA) was performed using the UnscramblerTM Version 10.3 software (CAMO). Two different pre-processing methods (smoothing followed by normalization) were performed on each of the three repeated spectrum measurements in the regions of $4000 \mathrm{~cm}^{-1}$ to $600 \mathrm{~cm}^{-1}$. Analysis of FTIR spectra datasets by PCA determines the differences between spectra in terms of chemical structure and composition of the samples [21].

\subsubsection{SEM Analysis}

SEM images of lignin and dried supernatant were captured using a Philips XL30 FEG ESEM scanning electron microscope operating at $10 \mathrm{kV}$ with various magnifications. Samples were coated with platinum for $120 \mathrm{~s}$ using Emscope SC500 sputter coater prior to analysis. 


\subsubsection{Particle Size Analysis}

The precipitated lignin and dried supernatant were dispersed at $10 \mathrm{mg} \mathrm{mL}^{-1}$ based on initial concentration of ethanol-water solutions (10\%, 25\%, and 50\% ethanol concentration). To achieve a good colloidal dispersion, the samples were ultrasound-treated for $10 \mathrm{~s}$ at room temperature using the 500W Fisher Scientific ${ }^{\mathrm{TM}}$ Model 505 Sonic Dismembrator prior to measurement. The diameter measurement was carried out in triplicate and the average reading of the results was reported.

\section{Malvern Zetasizer Nano ZS}

Lignin particle size was performed according to the protocols described with modification [22,23]. Lignin particle size was analyzed at $23^{\circ} \mathrm{C}$. The obtained size distribution represented the dependencies of the relative intensity of the scattered light on the hydrodynamic diameter of lignin particles.

\section{Malvern Mastersizer 2000}

A refractive index of 1.6 [24] and absorption of 0.01 for lignin were used by the instrument to calculate the particle size distribution [25]. The mean particle size was reported in terms of D3,2 values. The D3,2 is the surface area mean diameter and refers to the diameter of a sphere equivalent volume to surface area of the particles in the sample.

\subsubsection{Statistical Analysis}

SPSS software (Version 22) was used to carry out statistical analysis. Post hoc test by Tukey's honest significant different (HSD) was conducted at $\alpha=0.05$ to determine if the results obtained at each ethanol concentration were significantly different.

\section{Results and Discussion}

\subsection{Percentage of Lignin Recovery}

Figure 2 shows an increasing trend on percentage of lignin recovery as the ethanol co-solvent becomes more dilute. The post hoc test analysis illustrated that percentage of lignin recovery using $25 \%$ ethanol concentration $(71.4 \%)$ did not differ significantly from the $10 \%$ ethanol concentration $(75.8 \%)$, at a $95 \%$ confidence level. Lignin precipitation using $50 \%$ ethanol concentration only recovered $25.1 \%$ lignin. Further increasing the ethanol concentration to $75 \%$ led to zero recovery. The overall statistical analysis results were tabulated in Table 1.

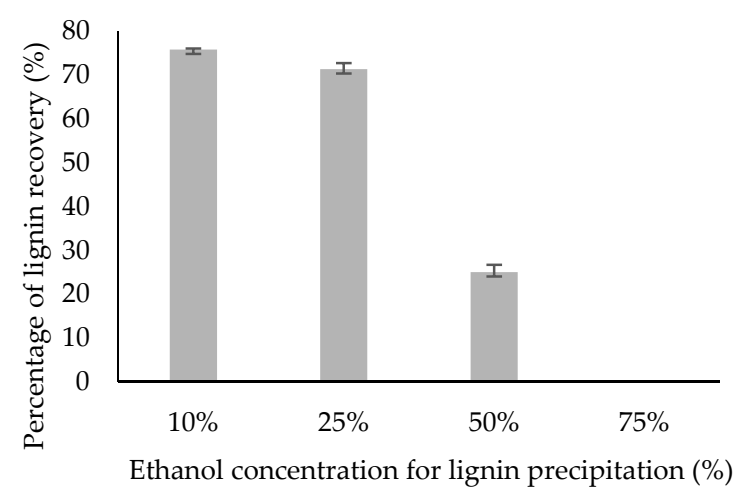

Figure 2. Percentage of lignin recovery at different ethanol concentration. 
Table 1. Analysis of Tukeytest for the assessment of ethanol concentration.

\begin{tabular}{|c|c|c|c|}
\hline Dependent Variable & $\begin{array}{l}\text { Percentage of Ethanol } \\
\text { Concentration }\end{array}$ & $\begin{array}{l}\text { Comparison with Other Percentage } \\
\text { of Ethanol Concentration }\end{array}$ & Sig. \\
\hline \multirow{6}{*}{$\begin{array}{l}\text { Percentage of purity } \\
\text { precipitated lignin }\end{array}$} & \multirow[b]{2}{*}{$50 \%$} & $25 \%$ & 0.857 \\
\hline & & $10 \%$ & 0.010 * \\
\hline & \multirow{2}{*}{$25 \%$} & $50 \%$ & 0.857 \\
\hline & & $10 \%$ & 0.010 * \\
\hline & \multirow[b]{2}{*}{$10 \%$} & $50 \%$ & $0.010 *$ \\
\hline & & $25 \%$ & 0.010 * \\
\hline \multirow{6}{*}{$\begin{array}{l}\text { Percentage of purity } \\
\text { dried supernatant }\end{array}$} & \multirow{2}{*}{$50 \%$} & $25 \%$ & $0.013 *$ \\
\hline & & $10 \%$ & 0.000 * \\
\hline & \multirow[b]{2}{*}{$25 \%$} & $50 \%$ & $0.000 *$ \\
\hline & & $10 \%$ & 0.525 \\
\hline & \multirow{2}{*}{$10 \%$} & $50 \%$ & $0.000 *$ \\
\hline & & $25 \%$ & 0.525 \\
\hline \multirow{6}{*}{$\begin{array}{l}\text { Percentage of lignin } \\
\text { recovery }\end{array}$} & \multirow{2}{*}{$50 \%$} & $25 \%$ & $0.000 *$ \\
\hline & & $10 \%$ & $0.000 *$ \\
\hline & \multirow{2}{*}{$25 \%$} & $50 \%$ & 0.000 * \\
\hline & & $10 \%$ & 0.100 \\
\hline & \multirow{2}{*}{$10 \%$} & $50 \%$ & $0.000 *$ \\
\hline & & $25 \%$ & 0.100 \\
\hline
\end{tabular}

Note: Numbers with asterix $(*)$ indicate statistically significant differences at the 0.05 level.

Critical precaution needs to be taken into consideration if water is added as the mixture of solution for delignification process. Based on the previous study within the research group, it is shown that the optimum delignification was achieved using ethanol:water ratio (1:1) [17] and similar concentration was used for delignification in this study. The optimal concentration of ethanol for delignification (1:1) is in agreement with the research conducted by Pasquini et al. [26]. The utilization of $100 \%$ ethanol is not preferred for delignification. The presence of both nucleophilic agents; water and ethanol produce a good solvent to promote the cleavage of lignin, and the capacity to dissolve the lignin fragments. With the addition of water, the nucleophilic agent stimulated the cleavage of the lignin but decreased the capability of the solvent to dissolve lignin in the delignification process [26]. High water content in the mixture of the solution for delignification may have demonstrated negative effects on delignification due to the nature of the hydrophobic biopolymer of lignin that could trigger adsorption of lignin fragments onto the surface of biomass fibers [27]. A suitable concentration of ethanol-water mixtures is desirable to avoid lignin re-precipitation onto the biomass fibers, thereby reducing the efficacy of delignification. Therefore, the best compromise between nucleophilicity and solubility of ethanol and water mixtures could promote good delignification.

Here, a new experiment looked at the addition of water to the soluble lignin extract was carried out after delignification for the purpose of lignin recovery study via centrifugation. In the lignin precipitation of ethanol pulping, the removal of lignin also depends on the capacity of aqueous ethanol solution to solubilise lignin fragments [26,28]. In a study with Alcell lignin and its solubility in ethanol-water mixtures, it was demonstrated that lignin solubility increased as the ethanol concentration increased until a maximum was reached at 70\% ethanol concentration [29]. When lignin precipitation is conducted by diluting liquor with water that decreased the amount of organic solvent, the solubility of lignin decreased, thus more lignin was recovered [28,30,31]. The findings were in agreement with the finding of Sun et al. which states that addition of anti-solvent such as ethanol, 1-propanol, and 1-butanol decreases the lignin solubility in the resultant system, therefore leading to a higher lignin recovery [32]. In general, it seems that a 10\% ethanol concentration could be proposed as the ethanol 
concentration for lignin recovery since there is no significant difference between lignin recovery using $25 \%$ and $10 \%$ ethanol addition.

\subsection{Percentage of Lignin Purity}

The resulting soluble lignin extract after delignification was fractionated according to different ethanol concentration under centrifugation thereby generating two fractions: precipitated and supernatant fraction. Both fractions were analyzed by Klason lignin assay to reveal the purity of lignin. A comparison between the three different ethanol concentrations is presented in Figure 3.

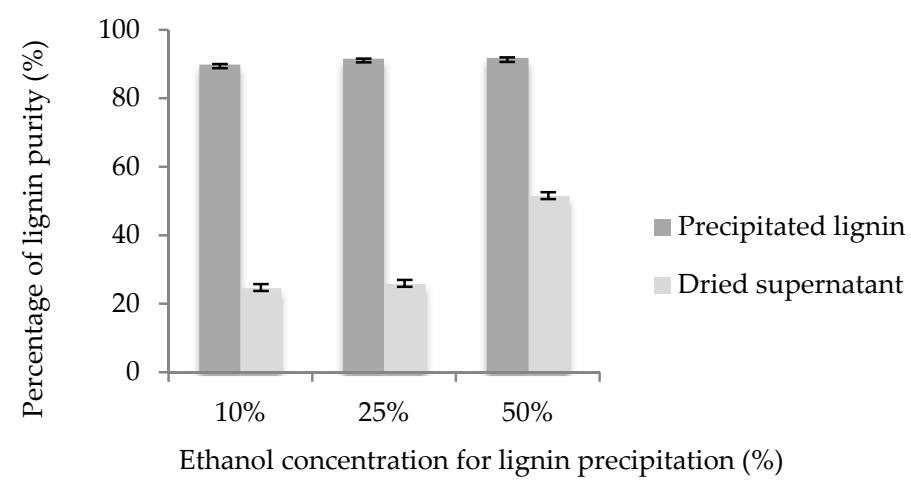

Figure 3. Percentage of lignin purity at different ethanol concentrations.

Overall, the purity of the obtained precipitated lignin consistently demonstrated a high purity $(\geq 90 \%)$. Such high purity lignin has enormous possibilities to be used in several industrial applications such as polymer blends, adhesives, and corrosion inhibitors [12,16,33]. A few studies have also reported high purity of lignin from the organosolv method, for instance, 95.4\% for sugarcane bagasse [34], $91.9 \%$ for $M x G$ [35], as well as $96.5 \%$ for shrub willow [25].

As it can be seen from Figure 3, the purity of lignin derived from dried supernatant obtained at $50 \%$ ethanol concentration is considerably higher than that of at $25 \%$ and $10 \%$. The high purity lignin derived from dried supernatant obtained at $50 \%$ ethanol concentration is due to less lignin that was precipitated as compared to other ethanol concentrations. Thus, more lignin remained with the impurities, as discussed in the FTIR analysis (Section 3.3). Considering that high dilution may lead to excessive energy costs if using $50 \%$ ethanol concentration, it is recommended to use $10 \%$ ethanol concentration for lignin precipitation process since there is no significant difference in the purity of the precipitated lignin using $50 \%$ and $25 \%$ ethanol concentrations.

\subsection{FTIR Analysis}

Figure 4a shows the PCA scores plot for the precipitated lignin and dried supernatant and it was elucidated that there were two definite clusters observed and were distinguishable within each other. Overall, the score plot for the dataset has functions, whose first two principles components explained $84 \%$ and $11 \%$ of the spectral variance, respectively. At the top are the spectra for the precipitated lignin at different ethanol concentration. A second cluster at the bottom consists of spectra for the dried supernatant. When comparison was made between similar types of spectra within samples, scores of precipitated lignin (10\%_L_1 and 10\%_L3, 25\%_L_1 and 25\%_L_3, 50\%_L_1 and 50\%_L_2) and scores of dried supernatant (10\%_S_1 and 10\%_S_2, 25\%_S_1 and 25\%_S_3, 50\%_S_1 and 50\%_S_2) were close to each other, indicating that the samples within similar type of spectra possess similar composition. Thus, a spectra was chosen only from the spectra with similar types to be analyzed for FTIR analysis. 


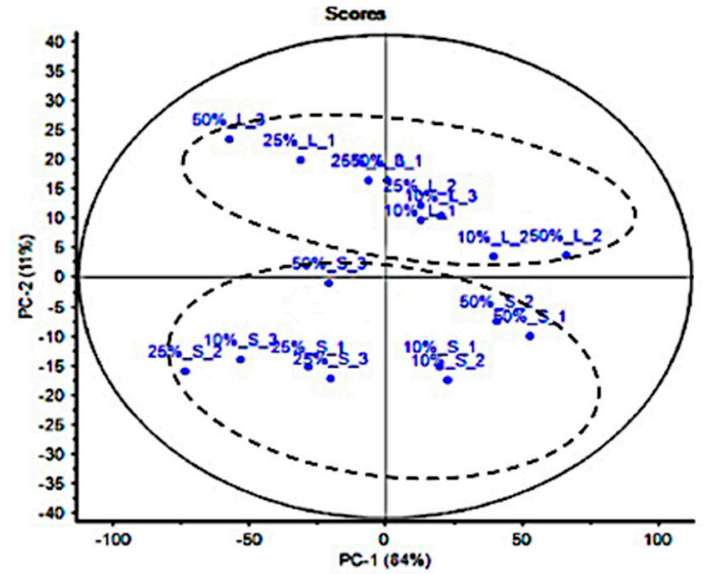

(a)

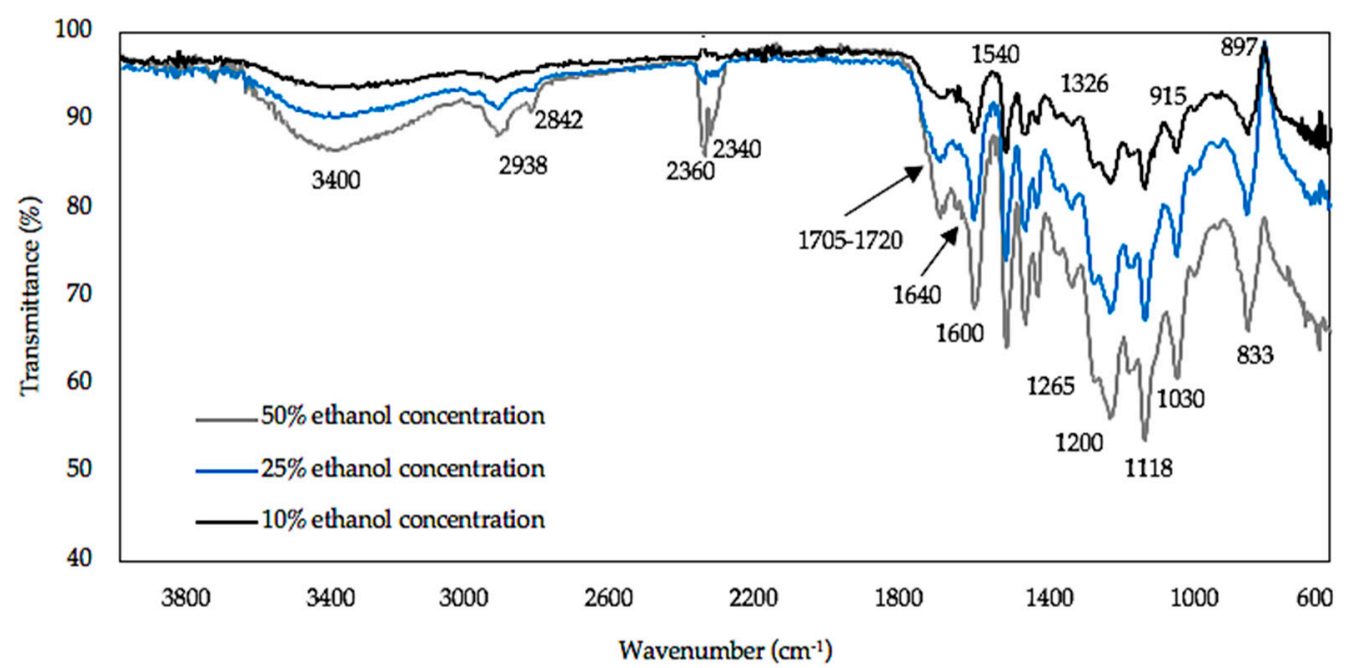

(b)

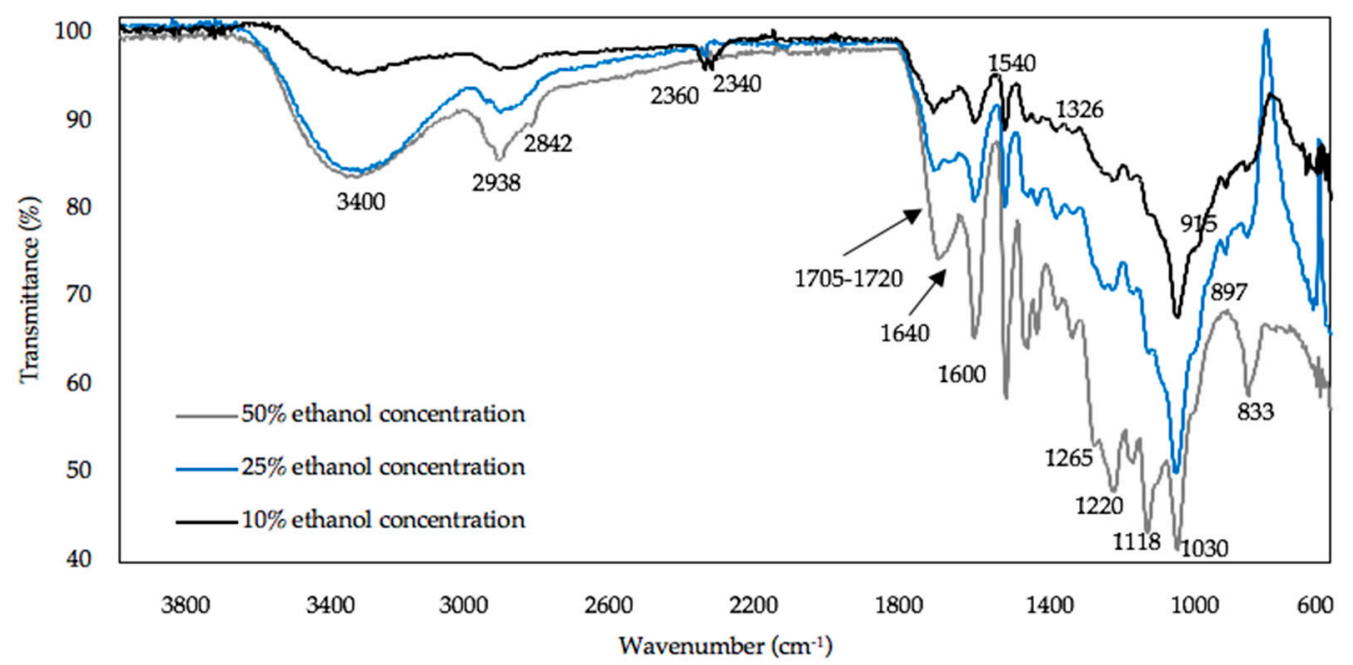

(c)

Figure 4. PCA and FTIR analysis at different ethanol concentrations. (a) PCA scores plot, (b) spectra of precipitated lignin, (c) spectra of dried supernatant. 
The spectra of precipitated lignin at different ethanol concentration are shown in Figure $4 \mathrm{~b}$. When comparison was made between the three spectra at different ethanol concentrations, the spectra at $50 \%$ ethanol concentration had a high intensity peak as compared to the other two spectra at $25 \%$ and $10 \%$, suggesting that a high intensity in peak indicates a high purity of lignin, especially at $3400 \mathrm{~cm}^{-1}$. The peak at $3400 \mathrm{~cm}^{-1}$ indicated the presence of $\mathrm{OH}$ stretching vibrations in aromatic and aliphatic $\mathrm{OH}$ groups [36,37]. The abundance of hydroxyl groups, demonstrating that lignin recovered can be a good alternative to polyols in the production of lignin polymer composites through lignin depolymerisation and modification at higher bio-replacement ratios [38]. However, when the hydroxyl group peak is of interest, strong water absorption (around $3000-4000 \mathrm{~cm}^{-1}$ ) could have influenced the results obtained and in turn, relatively led to the misinterpretation of the data. Therefore, the conclusion of the findings should be treated with caution, as the findings related to the availability of hydroxyl groups can be validated by various methods in future such as size exclusion chromatography and potentiometric titration, respectively.

The wavenumbers of $2938 \mathrm{~cm}^{-1}$ and $2842 \mathrm{~cm}^{-1}$ are attributed to $\mathrm{CH}$ stretching in aromatic methoxyl groups and in methyl and methylene groups of side chains [37]. An asymmetry and broadening of the peaks at $1705 \mathrm{~cm}^{-1}$ and $1600 \mathrm{~cm}^{-1}$ result from the weak absorption around $1640 \mathrm{~cm}^{-1}$ and may originate from both protein impurity and water associated with lignin, respectively [37]. The appearance of wavenumber at $1220 \mathrm{~cm}^{-1}$ is caused by the extraction process due to the hot water cleaved hemiacetal linkages, thus, liberating acids during biomass treatment which facilitate the breakage of ether linkages in biomass [39]. It is stated that the cleavage of O-acetyl groups and uronic acid substitutions on the hemicellulose released acids such as acetic and other organic acids which act as a catalyst, and catalyzed the formation and removal of oligosaccharides, and further hydrolyzed hemicellulose to monomeric sugars and aldehydes [40,41]. However, cellulose and hemicellulose appeared as contaminants as indicated by spectra wavenumbers at 897 and 1705 to $1720 \mathrm{~cm}^{-1}$. A wavenumber of $897 \mathrm{~cm}^{-1}$ represents amorphous cellulose which aids hydrolysis of the cellulose to glucose if enzymatic hydrolysis occurs [42]. The wavenumbers of 1705 to $1720 \mathrm{~cm}^{-1}$ are attributed to ester carbonyl vibration in acetyl, feryloyl, and $p$-coumaryl groups in hemicelluloses [43]. Wavenumbers of 2340 to $2360 \mathrm{~cm}^{-1}$ were found in all spectra and are related to $\mathrm{OH}$ stretching from strong H-bonded-COOH [44].

In general, hardwoods or angiosperms are made up of guaiacyl $(\mathrm{G})$ and syringl (S) units, while softwoods or gymnosperms contain only $\mathrm{G}$ units. Besides, grasses contain a variety of acidic guaiacyl units attached as esters and demonstrate more substitution of $p$-hydroxyphenyl units $(\mathrm{H})$ such as ferulic, hydroxycinnamic, and $p$-coumaric acids [45]. Lignin extracted from Miscanthus sp. contains all three lignin monomers, $\mathrm{G}, \mathrm{H}$, and $\mathrm{S}$ units $[7,46,47]$. This data showed that the wavenumbers related to $\mathrm{G}, \mathrm{H}$, and $\mathrm{S}$ units could be at $1326 \mathrm{~cm}^{-1}$ (G-S units), $1265,1030,915 \mathrm{~cm}^{-1}$ (G units), $1118,833 \mathrm{~cm}^{-1}$ (S units), $1705-1720 \mathrm{~cm}^{-1}$ (H units), and $2938,2842 \mathrm{~cm}^{-1}$ for $\mathrm{H}-\mathrm{S}$ units.

Supernatant obtained from the fractionation of the resulting soluble lignin extract at different ethanol concentration after centrifugation was dried for FTIR analysis (Figure 4c). In general, the spectra of $50 \%$ ethanol concentration had more broad intensity than $25 \%$ and $10 \%$ especially for wavenumbers apportioned to lignin. In fact, the supernatant has been proven to have the highest purity (51.6\%). The peaks for the dried supernatant related to lignin including wavenumbers of $2842,2340,2360,1640$, and $1326 \mathrm{~cm}^{-1}$ were in weaker intensity as compared to peaks of precipitated lignin. The weak intensity and absence of peaks $\left(915 \mathrm{~cm}^{-1}\right)$ related to lignin were due to more lignin precipitation and thus less lignin composition appeared in the dried supernatant. A peak of $1540 \mathrm{~cm}^{-1}$, related to an aromatic ring stretching in lignin, was found in both spectra for the precipitated lignin and the dried supernatant [48]. In summary, from the spectra in Figure 4c, it is apparent that wavenumbers of 897 and 1705 to $1720 \mathrm{~cm}^{-1}$ related to the contamination of cellulose and hemicellulose were in high intensity and resulted in broader peaks at 50\% ethanol concentration as compared to the $25 \%$ and $10 \%$ ethanol concentrations, thus the lignin derived from the supernatant had a lower purity level. 


\subsection{SEM Analysis}

When comparing the three samples of precipitated lignin at different ethanol concentrations, SEM images showed similarity in the presence of the lignin macromolecule globule structure of spherical balls or droplets. The shape of the lignin macromolecule was not identical in terms of size, as shown in Figure 5a-c. The precipitated lignin at 50\% ethanol concentration had a larger lignin macromolecule size than that of at $25 \%$ and $10 \%$. On the other hand, the precipitated lignin at $25 \%$ and $10 \%$ ethanol concentrations exhibited a mixture of large and small lignin macromolecules. In addition, it formed more colloidal and amorphous lignin macromolecule structure. A representative of SEM images of dried supernatant is exhibited in Figure $5 \mathrm{~d}-\mathrm{f}$ at $50 \%, 25 \%$, and $10 \%$ ethanol concentrations, respectively. SEM images at $50 \%$ ethanol concentration of dried supernatant revealed that a crystalline structure was observed in the dried supernatant as compared to that at $25 \%$ and $10 \%$. The dried supernatant at $25 \%$ and $10 \%$ ethanol concentrations had less crystalline and smooth surfaces as compared to that of at $50 \%$.

This is associated with the effect of surface area and particle size. Surface area is inversely proportional to particle size [49]. In a study of the effect of metal chlorides on the solubility of lignin in the black liquor of pre-hydrolysis kraft pulping, as the metal chlorides concentration increased, the particle size of lignin increased, hence the solubility of lignin decreased due to the increasing coagulation degree of lignin in the black liquor [50], thereby resulting in lower lignin precipitation. It is suggested that large particle size of lignin results in lower reaction surface area for the precipitation to take place. Therefore, less lignin is recovered.

The literature has emphasized the importance of ethanol concentration on lignin depolymerization. Findings revealed that there is a great increase in liquid residue from 41 to $65.5 \%$ by increasing ethanol concentration from 0 to 65 volume $\%$. Nevertheless, the solid residue yields decreased steadily from $39 \%$ to $17 \%$ [51]. The high ethanol concentration exerted a negative impact on the recovery of solid residue in lignin depolymerization. Therefore, the study would be more convincing if the molecular weight of the lignin obtained at different ethanol concentrations using different established methods such as gel permeation chromatography and size exclusion chromatography in addition to structural morphology could be obtained. Currently, efforts to increase the use of lignin in biopolymer applications is related to degradation or deconstruction of lignin to small monomers by depolymerization and chemical modification of lignin to increase reactive sites into lignin molecules [52,53]. The available reactive hydroxyl groups in lignin demonstrate possibilities for chemical modifications prior to lignin valorization into valuable materials [54]. Thus, molecular weight determination will enable the SEM data to be verified by independent techniques. 


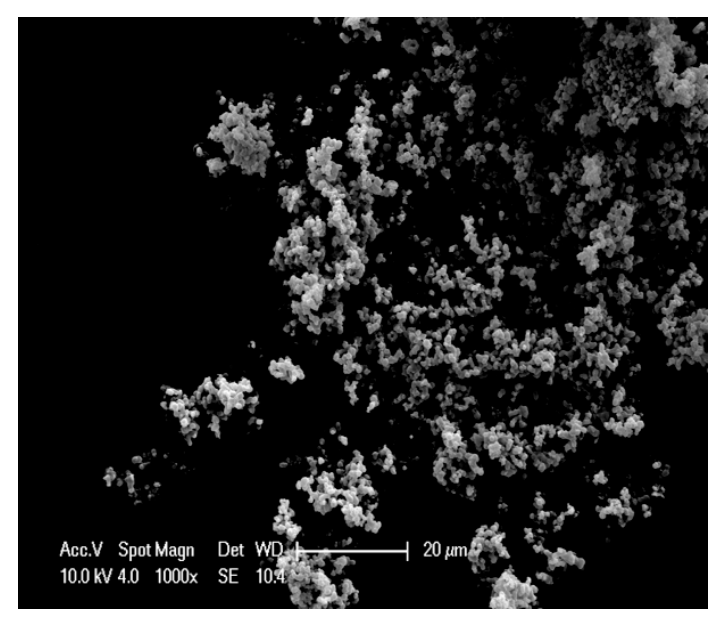

(a)

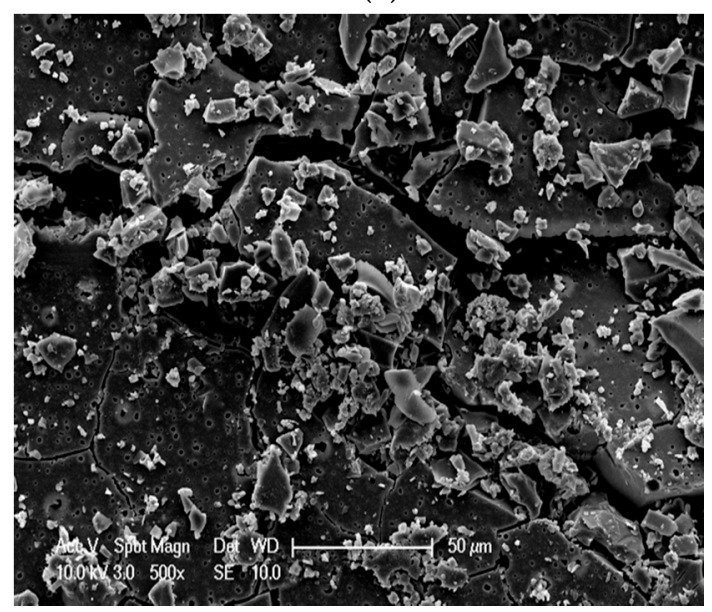

(d)

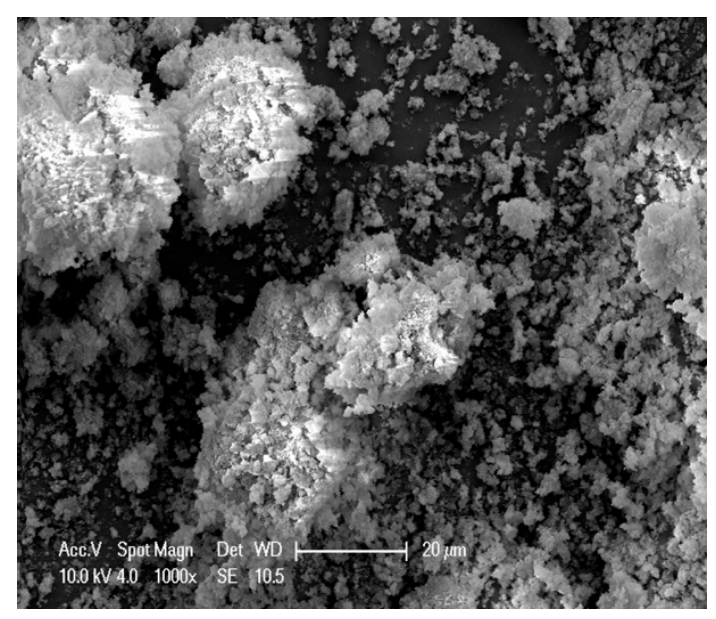

(b)

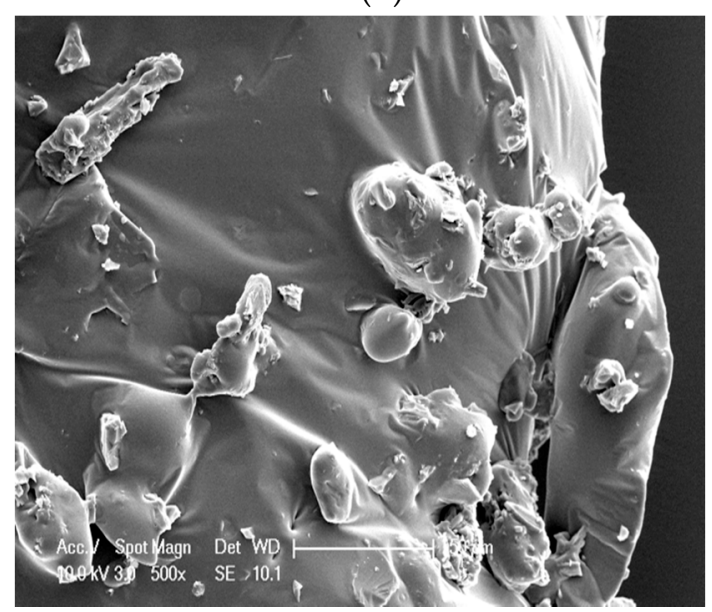

(e)

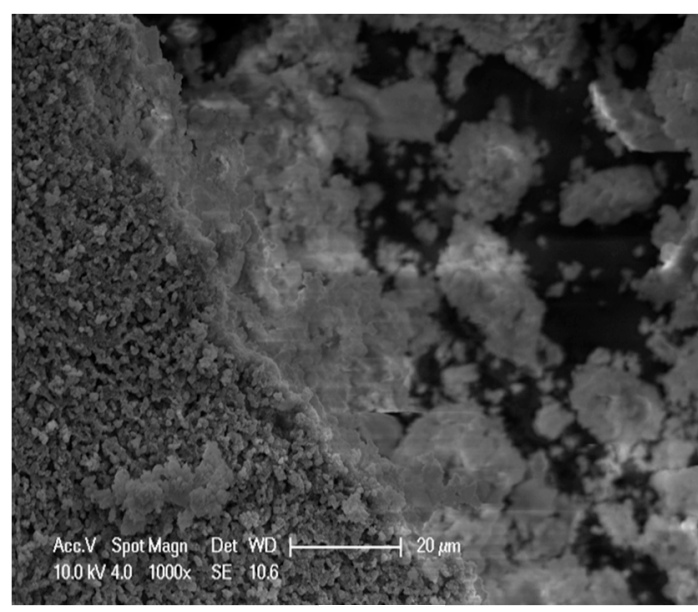

(c)

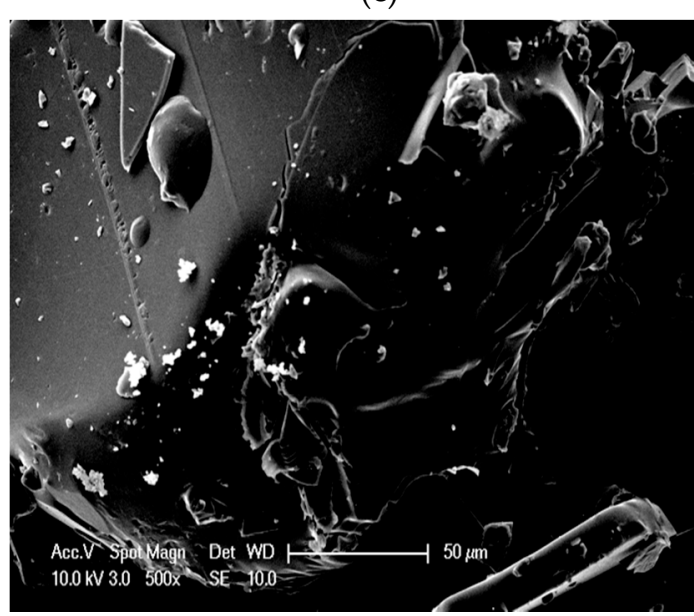

(f)

Figure 5. SEM images for precipitated lignin at (a) $50 \%$ ethanol concentration, (b) $25 \%$ ethanol concentration, (c) $10 \%$ ethanol concentration, and supernatant at (d) $50 \%$ ethanol concentration, (e) 25\% ethanol concentration, (f) $10 \%$ ethanol concentration. 


\subsection{Particle Size Analysis}

The data characterizing the particle size of lignin and the supernatant in different ethanol concentrations are presented in Table 2. A comparison between the three different ethanol concentrations using a Zetasizer illustrated that lignin precipitation at 50\% ethanol concentration had the highest average particle size $(2050.0 \mathrm{~nm})$ as compared to that of at $25 \%(391.7 \mathrm{~nm})$ and $10 \%(306.2 \mathrm{~nm})$ and the remaining dried supernatant had the lowest average particle size $(875.1 \mathrm{~nm})$ as compared to that of the $25 \%(1197.3 \mathrm{~nm})$ and $10 \%(1598.3 \mathrm{~nm})$. The particle size of respective lignin macromolecules can be explained using the SEM image analysis (Figure 5), especially the SEM image of the precipitated lignin at $50 \%$ ethanol concentration that clearly shows that lignin macromolecules have regular, uniform, and large shapes as compared to that of the $25 \%$ and $10 \%$. High average particle size of the precipitated lignin could also be due to the agglomeration of particles which reduces the surface area available for a precipitation reaction $[55,56]$. The surface area available during precipitation may influence the interaction of attractive and repulsive forces that further affects the lignin stability in solution and the lignin recovery process.

Table 2. Particle sizes of precipitated lignin and supernatant at different ethanol concentrations.

\begin{tabular}{|c|c|c|c|c|c|c|c|}
\hline \multirow{3}{*}{ Sample } & \multirow{3}{*}{$\begin{array}{c}\text { Ethanol } \\
\text { Concentration } \\
(\%)\end{array}$} & \multicolumn{6}{|c|}{ Particle Size } \\
\hline & & \multicolumn{2}{|c|}{$\begin{array}{l}\text { Particle Diameter from } \\
\text { Zetasizer Nano ZS (nm) }\end{array}$} & \multicolumn{4}{|c|}{$\begin{array}{l}\text { Particle Diameter from Mastersizes } \\
2000(\mu \mathrm{m})\end{array}$} \\
\hline & & $\begin{array}{l}\text { Particle Size } \\
\text { Distribution }\end{array}$ & $\begin{array}{l}\text { Particle } \\
\text { Size }\end{array}$ & ${ }^{1} \mathrm{D}_{\mathrm{v} 10}$ & ${ }^{2} D_{v 50}$ & ${ }^{3} D_{v 90}$ & ${ }^{4} D_{3,2}$ \\
\hline \multirow{3}{*}{ Lignin } & 50 & $\begin{array}{c}342.0-1281.0 \\
1281.0-6439.0\end{array}$ & 2050.0 & 5.5 & 98.2 & 257.7 & 18.3 \\
\hline & 25 & $\begin{array}{c}91.3-1718.0 \\
3580.0-6439.0\end{array}$ & 391.7 & 7.0 & 36.2 & 131.7 & 8.6 \\
\hline & 10 & $\begin{array}{c}58.8-295.3 \\
295.3-2669.0 \\
3580.0-6439.0\end{array}$ & 306.2 & 3.8 & 67.8 & 300.2 & 11.1 \\
\hline \multirow{3}{*}{ Supernatant } & 50 & $\begin{array}{c}68.1-295.3 \\
295.3-1484.0 \\
1484.0-6439\end{array}$ & 875.1 & 4.5 & 13.3 & 239.6 & 10.3 \\
\hline & 25 & $825.0-2305.0$ & 1197.3 & 3.0 & 9.3 & 86.3 & 6.9 \\
\hline & 10 & $531.2-6439.0$ & 1598.3 & 4.1 & 40.7 & 275.6 & 12.6 \\
\hline
\end{tabular}

Note: $\mathrm{D}=$ diameter; $\mathrm{v}=$ volume. ${ }^{1} \mathrm{D}_{\mathrm{v} 10}=$ the maximum particle diameter below which $10 \%$ of the sample volume exists. ${ }^{2} \mathrm{D}_{\mathrm{v} 50}=$ the maximum particle diameter below which $50 \%$ of the sample volume exists. ${ }^{3} \mathrm{D}_{\mathrm{v} 90}=$ the maximum particle diameter below which $90 \%$ of the sample volume exists. ${ }^{4} D_{3,2}=$ surface area mean diameter.

The $50 \%$ and $25 \%$ ethanol concentration had bimodal distributions whereas the $10 \%$ ethanol concentration of the precipitated lignin had multimodal distribution. The precipitated lignin at $25 \%$ and $10 \%$ ethanol concentration contains both nano- $(<100 \mathrm{~nm})$ and micro-size particles. The precipitated lignin at $50 \%$ ethanol concentration had only micro-size particles. The measured supernatant particles size at $10 \%$ and $25 \%$ ethanol concentration had a monomodal distribution whereas at $50 \%$ ethanol concentration, the supernatant showed a multimodal distribution. The supernatant of $25 \%$ and $10 \%$ ethanol concentration only had micro-particles whereby supernatant at $50 \%$ ethanol concentration contained both nano- and micro-particles. The resulting difference in particle size distributions for both precipitated lignin and supernatant may be due to the changes of physical and chemical properties; i.e., the samples in dried form, dispersed in the solution that cause the rearrangement of lignin macromolecules and the formation of new self-assembled structures [57].

Overall, the particle diameter of Mastersizer correlated with the patterns of particle size distribution of Zetasizer for both the precipitated lignin and dried supernatant. In general, reducing the ethanol 
concentration from $50 \%$ to $25 \%$ via Zetasizer results in a lower range of particle size distribution. A further reduction to $10 \%$ ethanol concentration showed that the distribution tends to move towards the right position of the distribution, demonstrating that the lignin particles tend to form a population of large particles within the precipitated lignin and dried supernatant.

Based on the data presented in Table 2, further distribution of Mastersizer results for precipitated lignin and dried supernatant are discussed. For precipitated lignin, reduction of 50\% to $25 \%$ ethanol concentration showed that $\mathrm{D}_{\mathrm{v} 10}$ increased in size from $5.5 \mu \mathrm{m}$ to $7.0 \mu \mathrm{m}$ and decreased to $3.8 \mu \mathrm{m}$ at $10 \%$ ethanol concentration. This indicates that the reduction of ethanol concentration from 50 to $10 \%$ ethanol concentration created large population of small particles. In contrast, $\mathrm{D}_{\mathrm{v} 50}$ and $\mathrm{D}_{\mathrm{v} 90}$ of the particle population exhibited different trends, whereby reducing ethanol concentration from $50 \%$ to $25 \%$ led to a descending trend in the size of lignin particles and ascending trend from $25 \%$ to $10 \%$ ethanol concentration. This showed that either re-aggregation of lignin particles occurred, or that lignin tends to form large particles at $10 \%$ ethanol concentration for $D_{v 50}$ and $D_{v 90}$ of the particle population $(67.8 \mu \mathrm{m}$ and $300.2 \mu \mathrm{m}$, respectively).

Similar findings were also observed for $D_{v 50}$ and $D_{v 90}$ of the particle population for supernatant, which showed an increment of lignin particle size at $10 \%$ ethanol concentration when compared to that of at $25 \%$ and $50 \%$ ethanol concentration. $D_{v 10}$ of the particle population showed different trends for supernatant. The particle size of $10 \%$ particle population $\left(\mathrm{D}_{\mathrm{v} 10}\right)$ decreased from $4.5 \mu \mathrm{m}$ (50\% ethanol concentration) to $3.0 \mu \mathrm{m}$ (25\% ethanol concentration) and increased to $4.1 \mu \mathrm{m}$ (10\% ethanol concentration). A possible explanation for various lignin aggregate behaviors may be the fact that lignin in an amphiphilic polymer contains both hydrophobic and hydrophilic segments besides possessing self-assembly behavior [58]. The hydrophilic segments of lignin macromolecules had an affinity to ethanol, whereas the hydrophobic segments dissociate lignin aggregate in ethanol-water mixture [58-61].

\section{Conclusions}

The focus of this study is primarily trying to understand the behavior of lignin aggregates and the study has raised important question on whether the effect of ethanol concentration influenced the behavior of lignin aggregates. In the present study, the effect of ethanol concentration was investigated on lignin recovery, particle size, chemical structure, and microscopy imaging properties. Findings showed that lignin recovery increased as the ethanol concentration decreased. Since there is no significant difference in the purity of precipitated lignin when using $50 \%$ and $25 \%$ ethanol concentration as compared to that of at $10 \%$, it is suggested that $10 \%$ ethanol concentration is used for lignin recovery. Moreover, at $10 \%$ ethanol concentration, the purity of precipitated lignin was high ( $\geq 90 \%)$. The results of lignin purity correlated well with the chemical structure analysis via FTIR. Both spectra of precipitated lignin and supernatant at 50\% ethanol concentration had higher intensity peak than $25 \%$ and $10 \%$ especially for wavenumbers apportioned to lignin. The morphology images captured via SEM imaging revealed the findings of particle size analysis.

Overall, it was demonstrated that the lignin macromolecule agglomerates which form post extraction could be de-agglomerated by reducing the ethanol concentration from $50 \%$ to $10 \%$. It is hypothesized that water had an influence on hygroscopic solvents i.e., different ethanol concentration that has different ability to attract and hold water molecules from the surrounding environment. Solvation of ethanol and water creates non-covalent interactions, such as hydrogen, Van der Waals and hydrophobic bonding that have a strong tendency to form aggregates with other molecules. The relationship between the solvent concentration and the resultant lignin macromolecule is complex. The present study is imperative and could facilitate an improved understanding on structural complexity of lignin for lignins obtained via SCW extraction. 
Author Contributions: Conceptualization, M.H.H.; Formal analysis, M.H.H.; Investigation, M.H.H.; Methodology, M.H.H.; Supervision, S.B. and P.C.; Validation, S.B. and P.C.; Writing-original draft, M.H.H.; Writing-review and editing, P.C. All authors have read and agreed to the published version of the manuscript.

Funding: This research was funded by Ministry of Higher Education Malaysia and Universiti Putra Malaysia under Skim Latihan IPTA and the APC was funded by Universiti Putra Malaysia.

Acknowledgments: The authors would also like to thank Phytatec (U.K.) Ltd. for providing biomass feedstock.

Conflicts of Interest: The authors declare no conflict of interest.

\section{References}

1. Wahid, R.; Nielsen, S.F.; Hernandez, V.M.; Ward, A.J.; Gislum, R.; Jørgensen, U.; Møller, H.B. Methane production potential from Miscanthus sp.: Effect of harvesting time, genotypes and plant fractions. Biosyst. Eng. 2015, 133, 71-80. [CrossRef]

2. Lanzerstorfer, C. Combustion of miscanthus: Composition of the ash by particle size. Energies 2019, 12, 178. [CrossRef]

3. Kryževičienè, A. Cultivation of Miscanthus $x$ giganteus for biofuel and its tolerance of Lithuania's climate. Zemdirb. Agric. 2011, 98, 267-274.

4. Wang, D.; Naidu, S.L.; Portis, A.R.; Moose, S.P.; Long, S.P. Can the cold tolerance of C4 photosynthesis in Miscanthus $x$ giganteus relative to Zea mays be explained by differences in activities and thermal properties of Rubisco? J. Exp. Bot. 2008, 59, 1779-1787. [CrossRef]

5. Xi, Q.; Jezowski, S. Plant resources of Triarrhena and Miscanthus species in China and its meanning for Europe. Plant Breed. Seed Sci. 2004, 49, 63-75.

6. Jørgensen, U. Benefits versus risks of growing biofuel crops: The case of Miscanthus. Curr. Opin. Environ. Sustain. 2011, 3, 24-30. [CrossRef]

7. Lewandowski, I.; Clifton-Brown, J.C.; Scurlock, J.M.O.; Huisman, W. Miscanthus: European experience with a novel energy crop. Biomass Bioenergy 2000, 19, 209-227. [CrossRef]

8. Glasser, W.G. About Making Lignin Great Again-Some Lessons From the Past. Front. Chem. 2019, 7, 1-17. [CrossRef]

9. Hamzah, M.H.; Bowra, S.; Cox, P. Purity and structural composition of lignin isolated from Miscanthus $x$ giganteus by sub-critical water extraction with associated modifiers. J. Agric. Food Eng. 2020, 1, 1-12.

10. Ratnaweera, D.R.; Saha, D.; Pingali, S.V.; Labbé, N.; Naskar, A.K.; Dadmun, M. The impact of lignin source on its self-assembly in solution. RSC Adv. 2015, 5, 67258-67266. [CrossRef]

11. Ganewatta, M.S.; Lokupitiya, H.N.; Tang, C. Lignin biopolymers in the age of controlled polymerization. Polymers 2019, 11, 1176. [CrossRef] [PubMed]

12. Lu, Y.; Lu, Y.C.; Hu, H.Q.; Xie, F.J.; Wei, X.Y.; Fan, X. Structural characterization of lignin and its degradation products with spectroscopic methods. J. Spectrosc. 2017, 1-15. [CrossRef]

13. Vishtal, A.; Kraslawski, A. Challenges in industrial applications of technical lignins. BioResources 2011, 6, 3547-3568.

14. Deng, Y.; Feng, X.; Zhou, M.; Qian, Y.; Yu, H.; Qiu, X. Investigation of aggregation and assembly of alkali lignin using iodine as a probe. Biomacromolecules 2011, 12, 1116-1125. [CrossRef]

15. Clauss, M.M.; Weldin, D.L.; Frank, E.; Giebel, E.; Buchmeiser, M.R. Size-exclusion chromatography and aggregation studies of acetylated lignins in N,N-dimethylacetamide in the presence of salts. Macromol. Chem. Phys. 2015, 216, 2012-2019. [CrossRef]

16. Matsakas, L.; Karnaouri, A.; Cwirzen, A.; Rova, U.; Christakopoulos, P. Formation of lignin nanoparticles by combining organosolv pretreatment of birch biomass and homogenization processes. Molecules 2018, 23, 1822. [CrossRef]

17. Roque, R.M.N. Hydrolysis of Lignocellulosic Biomass by a Modified organosolv Method on a Biorefinery Perspective-Example of Miscanthus $x$ Giganteus. Ph.D. Thesis, University of Birmingham, Birmingham, UK, 2013.

18. Mohan, M.; Banerjee, T.; Goud, V.V. Hydrolysis of bamboo biomass by subcritical water treatment. Bioresour. Technol. 2015, 191, 244-252. [CrossRef]

19. Rogalinski, T.; Liu, K.; Albrecht, T.; Brunner, G. Hydrolysis kinetics of biopolymers in subcritical water. J. Supercrit. Fluids 2008, 46, 335-341. [CrossRef] 
20. Sluiter, A.; Hames, B.; Ruiz, R.; Scarlata, C.; Sluiter, J.; Templeton, D.; Crocker, D. Determination of Structural Carbohydrates and Lignin in Biomass; National Renewable Energy Laboratory: Golden, CO, USA, 2012.

21. Durak, T.; Depciuch, J. Effect of plant sample preparation and measuring methods on ATR-FTIR spectra results. Environ. Exp. Bot. 2020, 169, 103915. [CrossRef]

22. Šurina, I.; Jablonskỳ, M.; Ház, A.; Sladková, A.; Briškárová, A.; Kačík, F.; Šima, J. Characterisation of non-wood lignin precipitated with sulphuric acid of various concentrations. BioResources 2015, 10, 1408-1423. [CrossRef]

23. Aleš, H.; Michal, J.; Lenka, D.; Alexandra, S.; Igor, Š. Thermal properties and size distribution of lignins precipitated with sulphuric acid. Wood Res. 2015, 60, 375-384.

24. Donaldson, L.A. Critical assessment of interference microscopy as a technique for measuring lignin distribution in cell walls. N. Z. J. For. Sci. 1985, 15, 349-360.

25. Stewart, H.E. Development of Food-Grade Microparticles From Lignin. Ph.D. Thesis, Massey University, Palmerston North, New Zealand, 2015.

26. Pasquini, D.; Pimenta, M.T.B.; Ferreira, L.H.; da Silva Curvelo, A.A. Extraction of lignin from sugar cane bagasse and Pinus taeda wood chips using ethanol-water mixtures and carbon dioxide at high pressures. J. Supercrit. Fluids 2005, 36, 31-39. [CrossRef]

27. Tu, Q.; Fu, S.; Zhan, H.; Chai, X.; Lucia, L.A. Kinetic modeling of formic acid pulping of bagasse. J. Agric. Food Chem. 2008, 56, 3097-3101. [CrossRef]

28. Xu, Y.; Li, K.; Zhang, M. Lignin precipitation on the pulp fibers in the ethanol-based organosolv pulping. Colloids Surf. A Physicochem. Eng. Asp. 2007, 301, 255-263. [CrossRef]

29. Ni, Y.; Hu, Q. Alcell lignin solubility in ethanol-water mixtures. J. Appl. Polym. Sci. 1995, 57, 1441-1446. [CrossRef]

30. Fernando, E.F. Lignin recovery from spent liquors from ethanol-water fractionation of sugar cane bagasse. Cellul. Chem. Technol. 2010, 44, 311-318.

31. Ortega, J.H. Process Design of Lignocellulosic Biomass Fractionation Into Cellulose, Hemicellulose and Lignin by Prehydrolysis and Organosolv Process. Master's Thesis, Wageningen University, Wageningen, The Netherlands, 2015.

32. Sun, J.; Dutta, T.; Parthasarathi, R.; Kim, K.H.; Tolic, N.; Chu, R.K.; Isern, N.G.; Cort, J.R.; Simmons, B.A.; Singh, S. Rapid room temperature solubilization and depolymerisation of polymeric lignin at high loadings. Green Chem. 2016, 18, 6012-6020. [CrossRef]

33. Hussin, M.H. Extraction, Modification and Characterization of Lignin From Oil Palm Fronds as Corrosion Inhibitors for Mild Steel in Acidic Solution. Ph.D. Thesis, Universite de Lorraine, Nancy and Metz, France, 2014.

34. Vallejos, M.E.; Felissia, F.E.; Curvelo, A.A.S.; Zambon, M.D.; Ramos, L.; Area, M.C. Chemical and physico-chemical characterisation of lignins obtained from ethanol-water fractionation of bagasse. BioResources 2011, 6, 1158-1171.

35. Bauer, S.; Sorek, H.; Mitchell, V.D.; Ibáñez, A.B.; Wemmer, D.E. Characterisation of Miscanthus $x$ giganteus lignin isolated by ethanol organosolv process under reflux condition. J. Agric. Food Chem. 2012, 60, 8203-8212. [CrossRef]

36. Alriols, M.G.; García, A.; Llano-Ponte, R.; Labidi, J. Combined organosolv and ultrafiltration lignocellulosic biorefinery process. Chem. Eng. J. 2010, 157, 113-120. [CrossRef]

37. Boeriu, C.G.; Bravo, D.; Gosselink, R.J.A.; van Dam, J.E.G. Characterisation of structure-dependent functional properties of lignin with infrared spectroscopy. Ind. Crops Prod. 2004, 20, 205-218. [CrossRef]

38. Mahmood, N.; Yuan, Z.; Schmidt, J.; Xu, C. Depolymerisation of lignins and their applications for the preparation of polyols and rigid polyurethane foams: A review. Renew. Sustain. Energy Rev. 2016, 60, 317-329. [CrossRef]

39. Behera, S.; Arora, R.; Nandhagopal, N.; Kumar, S. Importance of chemical pretreatment for bioconversion of lignocellulosic biomass. Renew. Sustain. Energy Rev. 2014, 36, 91-106. [CrossRef]

40. Mosier, N.; Wyman, C.; Dale, B.; Elander, R.; Lee, Y.Y.; Holtzapple, M.; Ladisch, M. Features of promising technologies for pretreatment of lignocellulosic biomass. Bioresour. Technol. 2005, 96, 673-686. [CrossRef] [PubMed]

41. Xiao, L.-P.; Sun, Z.-J.; Shi, Z.-J.; Xu, F.; Sun, R. Impact of hot compressed water pretreatment on the structural changes of woody biomass for bioethanol production. BioResources 2011, 6, 1576-1598. 
42. Mohamad Ibrahim, M.N.; Zakaria, N.; Sipaut, C.S.; Sulaiman, O.; Hashim, R. Chemical and thermal properties of lignins from oil palm biomass as a substitute for phenol in a phenol formaldehyde resin production. Carbohydr. Polym. 2011, 86, 112-119. [CrossRef]

43. Pandey, K.K. A study of chemical structure of soft and harwood and wood polymers by FTIR spectrscopy. J. Appl. Polym. Sci. 1999, 71, 1969-1975.

44. Davis, W.M.; Erickson, C.L.; Johnston, C.T.; Delfino, J.J.; Porter, J.E. Quantitative Fourier Transform Infrared spectroscopic investigation humic substance functional group composition. Chemosphere 1999, 38, 2913-2928. [CrossRef]

45. Holladay, J.E.; White, J.F.; Bozell, J.J.; Johnson, D. Top Value-Added Chemicals from Biomass; Pacific Northwest National Lab. (PNNL): Richland, WA, USA; National Renewable Energy Lab. (NREL): Golden, CO, USA, 2007.

46. Guo, F.; Shi, W.; Sun, W.; Li, X.; Wang, F.; Zhao, J.; Qu, Y. Differences in the adsorption of enzymes onto lignins from diverse types of lignocellulosic biomass and the underlying mechanism. Biotechnol. Biofuels 2014, 7, 38. [CrossRef]

47. Savy, D.; Cozzolino, V.; Vinci, G.; Nebbioso, A.; Piccolo, A. Water-Soluble Lignins from Different Bioenergy Crops Stimulate the Early Development of Maize (Zea mays, L.). Molecules 2015, 20, 19958-19970. [CrossRef] [PubMed]

48. Radotić, K.; Roduit, C.; Simonović, J.; Hornitschek, P.; Fankhauser, C.; Mutavdžić, D.; Steinbach, G.; Dietler, G.; Kasas, S. Atomic force microscopy stiffness tomography on living arabidopsis thaliana cells reveals the mechanical properties of surface and deep cell-wall layers during growth. Biophys. J. 2012, 103, 386-394. [CrossRef] [PubMed]

49. Kumar, A.; Kumar, J.; Bhaskar, T. Utilization of lignin: A sustainable and eco-friendly approach. J. Energy Inst. 2020, 93, 235-271. [CrossRef]

50. He, L.; Liu, Q.; Song, Y.; Deng, Y. Effects of metal chlorides on the solubility of lignin in the black liquor of prehydrolysis kraft pulping. BioResources 2014, 9, 4636-4642. [CrossRef]

51. Ye, Y.; Zhang, Y.; Fan, J.; Chang, J. Novel method for production of phenolics by combining lignin extraction with lignin depolymerisation in aqueous ethanol. Ind. Eng. Chem. Res. 2012, 51, 103-110. [CrossRef]

52. Xu, C.; Arneil, R.; Arancon, D.; Labidi, J.; Luque, R. Lignin depolymerisation strategies: Towards valuable chemicals and fuels. Chem. Soc. Rev. 2014, 43, 7485-7500. [CrossRef] [PubMed]

53. Matsushita, Y.; Yasuda, S. Reactivity of a condensed-Type lignin model compound in the Mannich reaction and preparation of cationic surfactant from sulfuric acid lignin. J. Wood Sci. 2003, 49, 166-171. [CrossRef]

54. Duval, A.; Lawoko, M. A review on lignin-based polymeric, micro- and nano-structured materials. React. Funct. Polym. 2014, 85, 78-96. [CrossRef]

55. Allen, E.; Smith, P.; Henshaw, J. A Review of Particle Agglomeration; AEA Technology: Dorset, UK, 2001.

56. Sayyar, S.; Abidin, Z.Z.; Yunus, R.; Muhammad, A. Extraction of oil from Jatropha seeds-optimisation and kinetics. Am. J. Appl. Sci. 2009, 6, 1390-1395. [CrossRef]

57. Shulga, G.; Vitolina, S. Lignin separated from the hydrolysate of the hydrothermal treatment of birch wood and its surface properties. Cellul. Chem. Technol. 2012, 46, 307-318.

58. Xiong, F.; Han, Y.; Wang, S.; Li, G.; Qin, T.; Chen, Y.; Chu, F. Preparation and formation mechanism of size-controlled lignin nanospheres by self-assembly. Ind. Crops Prod. 2017, 100, 146-152. [CrossRef]

59. Qian, Y.; Deng, Y.; Qiu, X.; Li, H.; Yang, D. Formation of uniform colloidal spheres from lignin, a renewable resource recovered from pulping spent liquor. Green Chem. 2014, 16, 2156. [CrossRef]

60. Li, H.; Deng, Y.; Liu, B.; Ren, Y.; Liang, J.; Qian, Y.; Qiu, X.; Li, C.; Zheng, D. Preparation of Nanocapsules via the Self-Assembly of Kraft Lignin: A Totally Green Process with Renewable Resources. ACS Sustain. Chem. Eng. 2016, 4, 1946-1953. [CrossRef]

61. Rao, X.; Liu, Y.; Zhang, Q.; Chen, W.; Liu, Y.; Yu, H. Assembly of Organosolv Lignin Residues into Submicron Spheres: The Effects of Granulating in Ethanol/Water Mixtures and Homogenisation. ACS Omega 2017, 2, 2858-2865. [CrossRef] [PubMed]

(C) 2020 by the authors. Licensee MDPI, Basel, Switzerland. This article is an open access article distributed under the terms and conditions of the Creative Commons Attribution (CC BY) license (http://creativecommons.org/licenses/by/4.0/). 